\title{
PATRIMONIO CULTURAL Y DESARROLLO TERRITORIAL
}

Jemay Mosquera Téllez

jemurb@unipamplona.edu.co

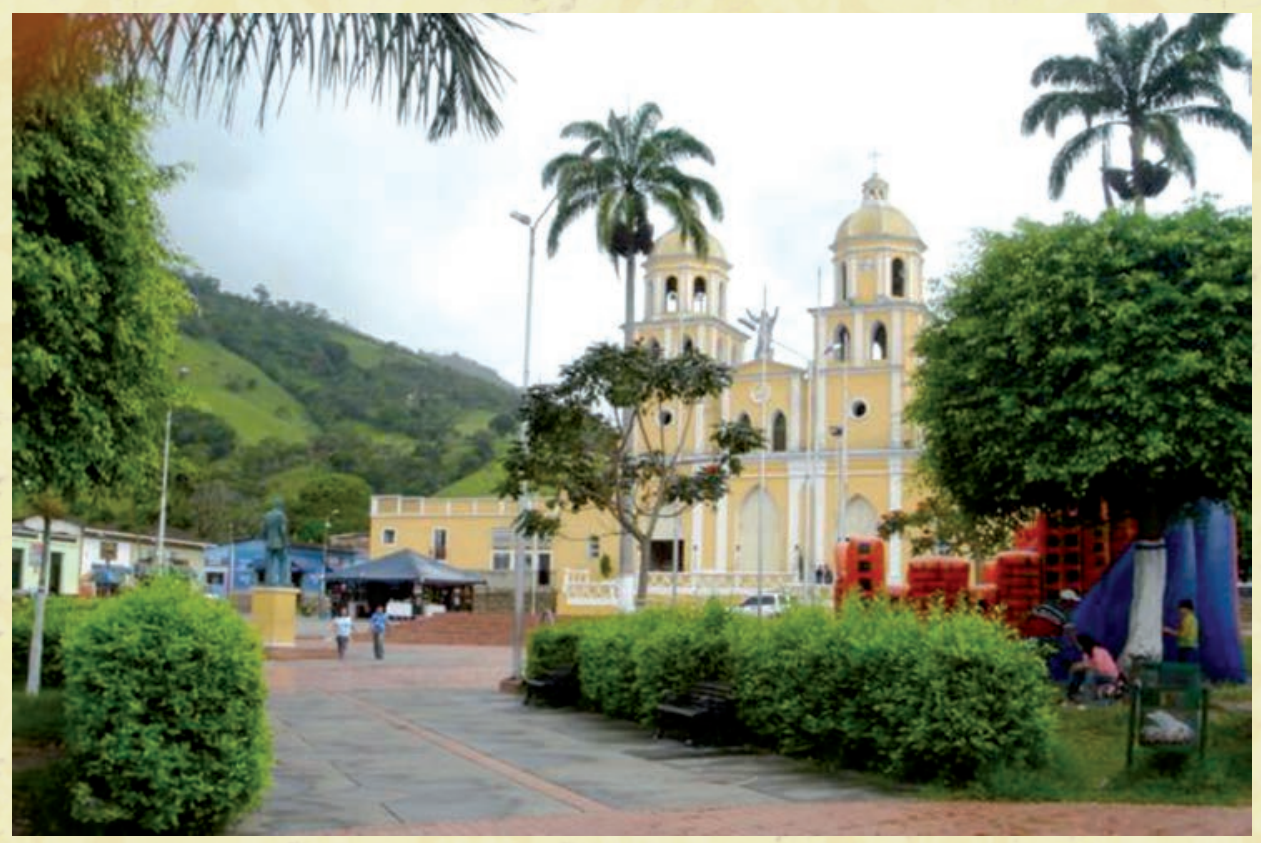

\section{Resumen}

La propuesta parte de fundamentar la gestión integral del territorio en principios orientadores humanísticos y ecológicos y en estrategias flexibles que responden directamente a cada uno de los sistemas que inciden en el territorio, pero al mismo tiempo se propone adoptar una concepción sistémica del mundo considerando a los sistemas social y cultural como suprasistemas que permiten abordar la interpretación general del mundo desde lo social y la generación de alternativas de desarrollo endógeno a partir del patrimonio cultural tangible e intangible como elemento fundamental para consolidar la territorialidad y lograr un desarrollo armónico y sinérgico desde lo local. En particular, se propone mapificar y espacializar, a partir de herramientas metodológicas participativas, los conflictos culturales y los tangibles e intangibles patrimoniales más representativos del sistema cultural, como prerrequisito fundamental para la generación de nuevos enfoques de desarrollo regional, basados en la definición de objetivos comunes que permitan enfrentar y construir proyectos asociativos que tengan legitimidad, que potencialicen las múltiples identidades locales y que fortalezcan la participación de la población en la construcción de las identidades regionales enfocadas al logro colectivo de un desarrollo integral del territorio.

\section{Palabras claves}

Patrimonio, modelo de datos, planeación participativa 


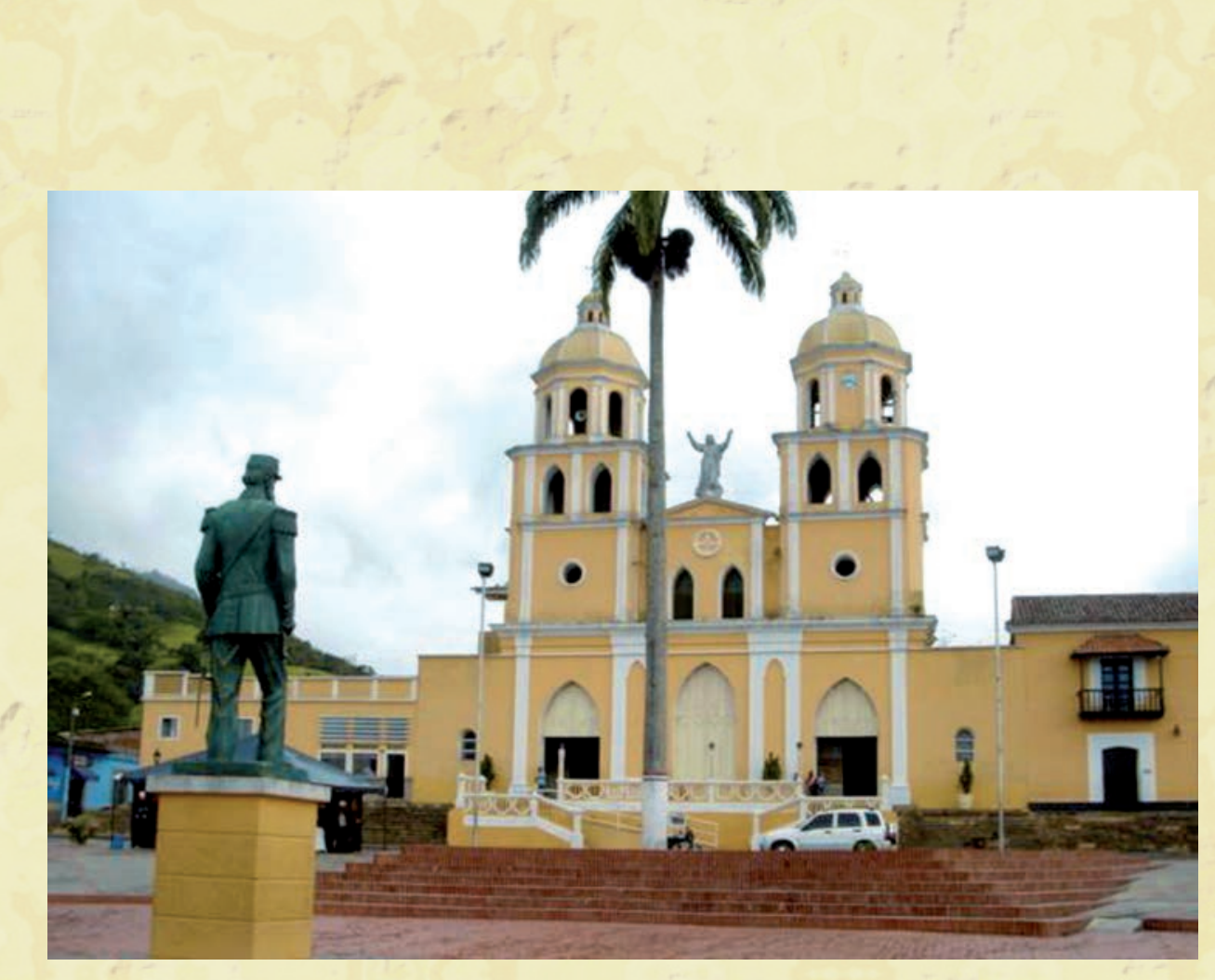

\section{Abstract}

The proposal starts from laying the foundations of the integral maneuver of the territory in humanistic and ecological principles of orientation and in flexible strategies that directly respond to each one of the systems that impact in the territory, but at the same time intends to adopt a systemic conception of the world considering the social and cultural systems as suprasystems that allow to approach the general interpretation of the world from the social thing and the generation of alternative endogenous development starting from the tangible and intangible cultural patrimony as fundamental element to consolidate the territoriality and to achieve a harmonic and synergic development from the local thing. In particular, it intends to map and space, starting from methodological participative tools, the cultural conflicts and the tangible and intangibles representative patrimonial of the cultural system, as fundamental prerequisite for the generation of new regional development focuses, based on the definition of common objectives that allow to face and to build associative projects that have genuineness, that power up the multiple local identities and that they strengthen the population's participation in the construction of the regional identities focused to the collective achievement of an integral development of the territory.

\section{Key words}

Heritage, model of data, participative planning
Doctor en Arquitectura Líder Grupo de investigación Gestión Integral del Territorio - GIT jemurb@unipamplona.edu.co Universidad de Pamplona. Casa Central. 


\section{PATRIMONIO CULTURAL Y DESARROLLO TERRITORIAL}

Los cambios estructurales observados en la evolución del mundo contemporáneo son marcados por una gran complejidad. El nuevo orden económico en el cual se desenvuelve el funcionamiento de las ciudades exige de estas la optimización de su nivel de competitividad empresarial local, inversión en tecnología, incursión en mercados exteriores y capacitación de sus recursos humanos. Todo ello basado en la creación y uso de ventajas competitivas dinámicas, construidas a partir del conocimiento y de la innovación permanente.

En ese sentido, la gestión integral del territorio requiere nuevas construcciones mentales de percepción conciente del contexto espacio temporal que habitamos y demanda nuevos métodos de análisis, innovación tecnológica y aplicación de un enfoque transdisciplinario, sistémico, holístico y hologramático que permita solucionar los conflictos de uso del territorio de manera no lineal, teniendo en cuenta las necesidades reales de la comunidad y los intereses de los agentes protagónicos del desarrollo local.

En Colombia, los procesos de uso y ocupación del territorio se han caracterizado por una gran dinámica e incertidumbre. Actualmente, estos procesos responden cada vez más a externalidades $\mathrm{o}$ a los cambios asociados a la apertura económica en el contexto de una economía global y se manifiestan por medio de una relativa autonomía de los entes territoriales, fundamentada en las leyes que acompañan el proceso en curso de descentralización y modernización del estado colombiano. En lo que respecta al departamento de Norte de Santander, se encuentra en la región del nororiente colombiano y cuenta con una ubicación estratégica en el contexto nacional, con una infraestructura vial y de servicios en proceso de optimización, atractivos naturales y culturales y una estructura jerárquica de ciudades enmarcada en un sistema policéntrico regional, lo cual le genera una serie

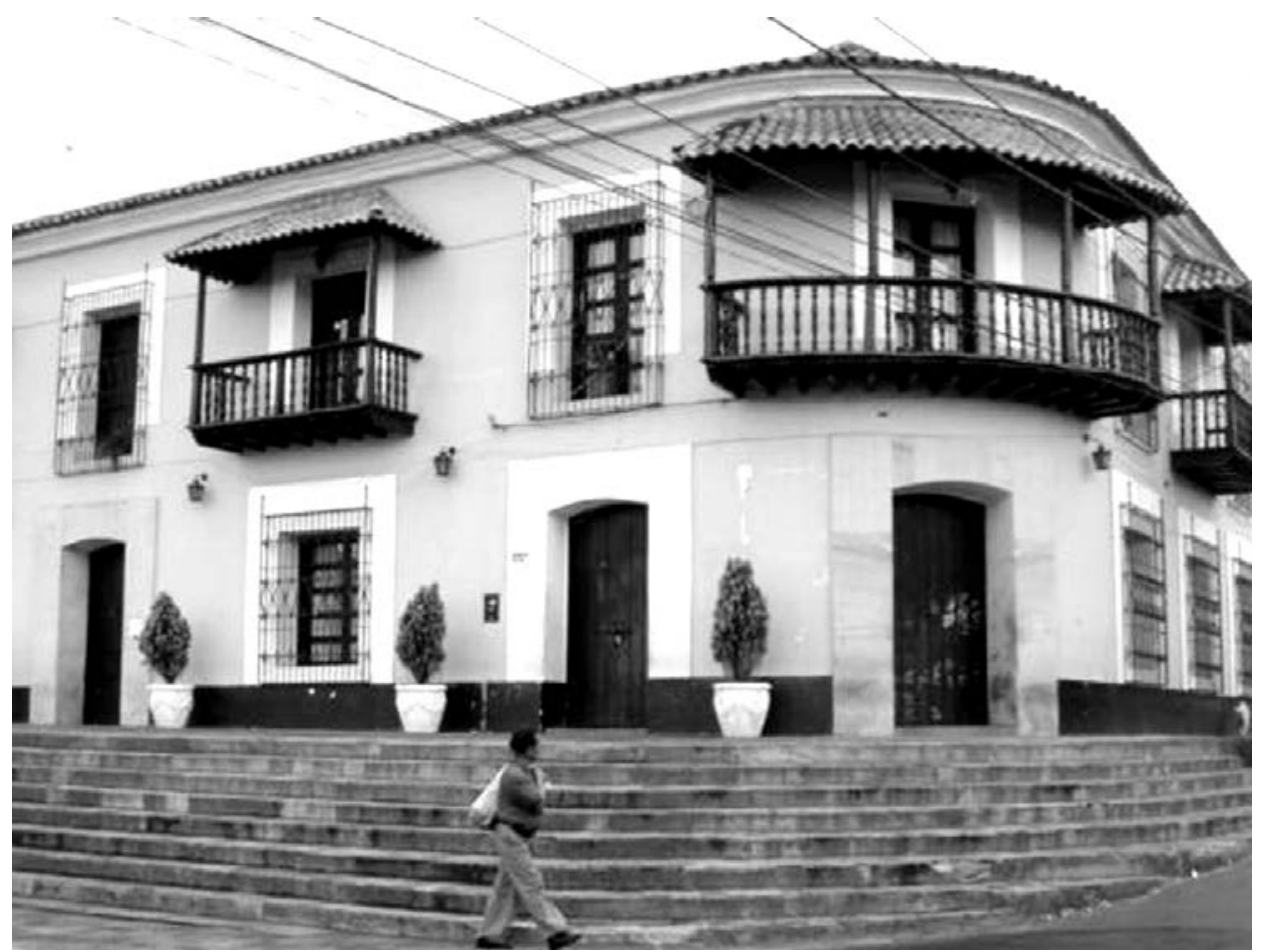

Chinácota, foto: Jemay Mosquera 
de ventajas comparativas que lo pueden convertir en un centro de servicios y en destino turístico nacional.

Adicionalmente, la ocupación del territorio del departamento de Norte de Santander presenta momentos cruciales, desde la existencia de pobladores indígenas anterior a la conquista, la localización de asentamientos humanos en tiempos de la colonia española y la influencia multifactorial recíproca con la república de Venezuela, hechos que hoy se ven reflejados en el territorio y en las actividades humanas que en él se desarrollan.

No obstante lo anterior, dicho lugar habitado ha sido escaso objeto de estudio por parte de los arquitectos, urbanistas, ingenieros y demás profesionales que generan y construyen los espacios urbanos, puesto que ignoran o encuentran dificultades en la articulación de su objeto de estudio con otras disciplinas y de los hechos físicos con los intangibles, dificultades en la comprensión y contextualización de los procesos y las dinámicas urbanas locales, las cuales han traído como consecuencia la transformación de elementos urbanos tradicionales en lugares hostiles e inseguros (Augé, 1993). Al mismo tiempo, ante la ausencia de herramientas pedagógicas y metodológicas que suplan la necesidad de entender y operar eficientemente el espacio habitado, cada vez se agranda más la brecha entre ciudad, ciudadanos y urbanistas que impiden ser actores y gestores del proceso de desarrollo local y regional y propician el aislamiento y la confusión entre el sujeto social conciente o inconciente y el objeto de estudio arquitectónico (Pérgolis, 1998).

Para abordar la realidad del departamento nortesantandereano es necesario dar un salto cualitativo en la forma de atender los problemas y para ello se requiere pasar de salidas inmediatistas a soluciones estructurales, que sólo son posibles de concebir en un horizonte de largo plazo, y crear las condiciones necesarias para aprovechar exitosamente las oportunidades que ofrece el futuro y también realizar acciones de protección para evitar los impactos de los posibles eventos negativos.

En este aspecto de construcción del estado, la territorialidad y el sistema regional juegan un rol fundamental, en su reordenamiento territorial pues dan cuenta de las particularidades locales y de la compleja interrelación de los procesos sociales, culturales, económicos, ambientales y político administrativos que originan y estructuran el sistema regional (Borja, 2000). Por lo tanto, es el momento de entender la dimensión del reto histórico, de ver el desarrollo regional y local como materia de reflexión y análisis, con el fin de asimilar los aciertos y desaciertos de su concepción y ejecución.

En esta transición metodológica, conceptual y operativa, una labor fundamental de la gestión integral del territorio radica en la necesidad de la protección de la diversidad y riqueza étnica, cultural y natural, así como en el fortalecimiento de la participación social, es decir, en la participación activa de los actores e instituciones, agentes homogéneos o heterogéneos y la adquisición de compromisos por parte de los mismos, la socialización de los informes y resultados y el logro de institucionalidad mediante acuerdos de voluntades para su concreción. En ese sentido, es primordial que el sistema cultural prevalezca sobre las acciones tendientes a consolidar una visión transdisciplinaria y holística del territorio y genere las condiciones para realizar una gestión certera y responsable del desarrollo territorial. Es imprescindible fortalecer el rol del sistema cultural en el desarrollo de la región, en la definición de alternativas apropiadas de uso y ocupación del territorio, ajustadas a las políticas y estrategias de desarrollo territorial. 
La propuesta se genera desde un cambio paradigmático de cómo abordar la realidad de manera integral a partir de una visión holística y hologramática que nos permite comprender la cultura y la constitución de la sociedad en la medida en que somos el reflejo de la sociedadcultura que al mismo tiempo nos refleja, es decir “... el todo está incluido en la parte que está incluida en el todo”. (Morín, 1997). Se propone entonces, asumir el territorio como un sistema complejo adaptativo compuesto por múltiples componentes en interacción nolineal continua y con capacidad de auto-reorganización (Holland, 1995), y fundamentar el desarrollo en principios orientadores humanísticos y ecológicos y en estrategias flexibles que responden directamente a cada uno de los "sistemas" (Lineamientos para el ordenamiento territorial departamental, 1997) que inciden en el territorio (ver Tabla I). Al mismo tiempo, se propone adoptar una concepción suprasistémica del mundo considerando a los sistemas social y cultural como suprasistemas que permiten abordar la interpretación general del mundo desde lo social y la generación de alternativas de desarrollo endógeno a partir de lo cultural, del patrimonio tangible e intangible, como elementos fundamentales para consolidar la territorialidad, para conservar y fortalecer nuestras identidades o individualidades, para lograr un desarrollo armónico y sinérgico desde lo local. Se asume también, al sistema ambiental, como sistema articulador contenido en los dos suprasistemas y contenedor de los sistemas económico y político administrativo, los cuales se apropiarán en función de lo socio cultural y lo ambiental (ver Gráfica I).

Tabla I. Visión del territorio desde el enfoque sistémico

\begin{tabular}{|c|c|c|}
\hline SISTEMA & PRINCIPIOS & TEMAS ESTRUCTURANTES \\
\hline Social & Equidad & $\begin{array}{l}\text { Inclusión, de la pobreza y la desigualdad a la inclusión, el } \\
\text { derecho a la ciudad y la construcción de alteridad }\end{array}$ \\
\hline Cultural & Identidades & $\begin{array}{l}\text { Reconocimiento a las identidades, a los procesos de trans- } \\
\text { culturización y construcción de alteridad. }\end{array}$ \\
\hline Ambiental & Sostenibilidad & $\begin{array}{c}\text { Sostenibilidad, vulnerabilidad y riesgo, naturaleza como } \\
\text { sujeto de derechos, derechos colectivos y responsabili- } \\
\text { dades compartidas. }\end{array}$ \\
\hline Económico & $\begin{array}{l}\text { Competitividad } \\
\text { a escala humana }\end{array}$ & $\begin{array}{l}\text { Inserción en los mercados internacionales, atracción e } \\
\text { incorporación de tecnología, estructuras económicas y } \\
\text { entornos dinámicos. }\end{array}$ \\
\hline $\begin{array}{l}\text { Político } \\
\text { Administrativo }\end{array}$ & Gobernabilidad & $\begin{array}{l}\text { Actores protagónicos del desarrollo, gobernabilidad y } \\
\text { gobernancia }\end{array}$ \\
\hline
\end{tabular}

Fuente: Grupo de Investigación Gestión Integral del Territorio - GIT

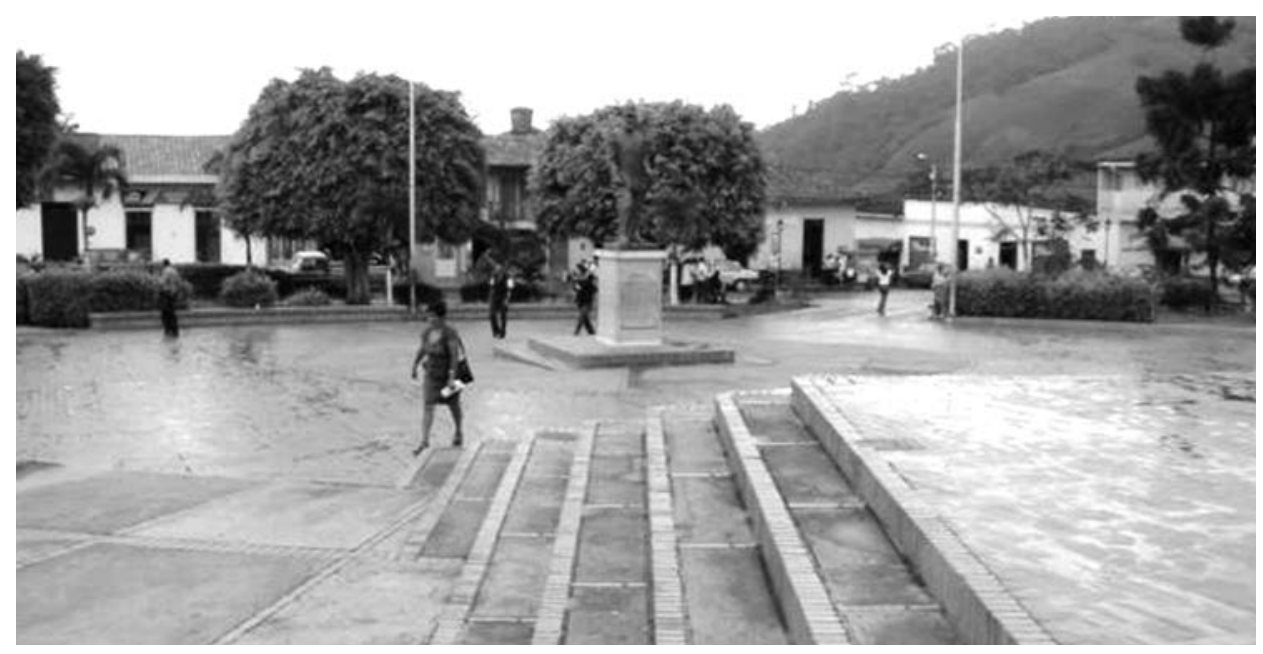

Parque Chinácota, foto: Jemay Mosquera 
Desde esta concepción cultural del desarrollo social y del conocimiento transdisciplinar basado en el pensamiento analítico, crítico y reflexivo sobre los cambios integrales del mundo globalizado, se puede interpretar y optimizar la región y las municipalidades con políticas de fortalecimiento intra e interinstitucional desde la gestión integral del territorio; entendida ésta, como la concertación, coordinación e integración de políticas, estrategias, programas y proyectos entre los diferentes agentes y sectores protagonistas del desarrollo regional.

Gráfica I. Modelo de ordenamiento territorial propuesto

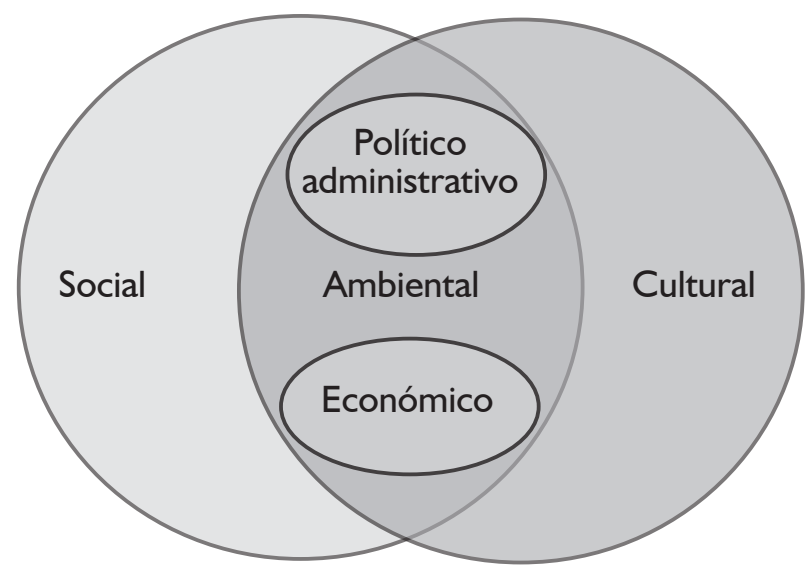

Fuente: Grupo de Investigación Gestión Integral del Territorio - GIT

La propuesta se enmarca además, en la teoría de la resonancia mórfica, la cual se basa en las nociones de los campos morfogenéticos (Weiss, 1939) y concibe que la naturaleza no está regida por leyes inmutables, constantes y precisas, sino evolutivas, con memoria acumulativa y capacidad de propagación por medio de un proceso de conexión inmaterial, asumiendo que las constantes no son más que el reflejo temporal de hábitos que se pueden recuperar y fortalecer (Sheldrake, 1990). De esta manera, si creamos hábitos sólidos (patrones espacio temporales) en nuevas estructuras colectivas, entonces este hábito contenedor de memoria acumulativa se incorporará como campo mórfico a esa comunidad, influirá en ella de forma evolutiva a través del tiempo y el espacio, traerá consigo implicaciones de ajuste y autoorganización en todos los ámbitos del desarrollo humano.

Dicho de otra manera, la resonancia mórfica es la vía mediante la cual el conocimiento se transmite, independiente del espacio y el tiempo, de manera instantánea, en la medida que la estructura de los espacios posee una memoria acumulativa basada en lo que le ha ocurrido al lugar habitado en el pasado (costumbres, tradiciones, entre otros) y que le afectan la conducta de los hábitos de hoy. El campo mórfico se encuentra entonces, en el exterior de cada individuo, en su entorno asumido como depositario de la información esencial que le permite su desarrollo, como fuente y origen de sentimientos, hábitos y tradiciones que, si bien no pertenecen al mundo físico, se constituyen en la memoria colectiva de una comunidad.

Ahora bien, la formulación de los principios humanísticos y ecológicos y las estrategias flexibles enunciadas anteriormente se puede lograr mediante la elaboración e implementación de un modelo digital del territorio que permita, sobre la base de la interacción 
y superposición de múltiples datos, variables e indicadores generados a partir de cada sistema, acercarnos a una comprensión acertada de la realidad. En particular, se propone mapificar y espacializar, a partir de herramientas metodológicas participativas, los conflictos culturales y los tangibles e intangibles patrimoniales más representativos del sistema cultural, como prerrequisito fundamental para la generación de nuevos enfoques de desarrollo regional, basados en la definición de objetivos comunes que permitan enfrentar y construir proyectos asociativos, sistemas y redes de ciudades que tengan legitimidad, que potencialicen las múltiples identidades locales y que fortalezcan la participación de la población en la construcción de las identidades regionales enfocadas al logro colectivo de un desarrollo armónico y sostenible.

Se pretende entonces, generar un modelo de datos construyéndolo con los pobladores del lugar habitado por nuestra conciencia. En primera instancia se genera la información relacionada con los elementos tangibles e intangibles del sistema cultural y al interior de éste los relacionados con el patrimonio por ser éste el que cuenta con más significado y sentido y, por tanto, forma parte de esa sustancia del deseo por las formas que habitan nuestra conciencia, entre las cuales se encuentra la forma Arquitectónica (ver Tabla 2).

Tabla 2. Modelo de datos del patrimonio cultural

\begin{tabular}{|c|c|c|c|}
\hline \multicolumn{4}{|c|}{ SISTEMA CULTURAL } \\
\hline \multicolumn{4}{|c|}{ PATRIMONIO TANGIBLE E INTANGIBLE } \\
\hline TEMAS & GRUPOS DE OBJETOS & OBJETOS & ATRIBUTOS \\
\hline $\begin{array}{l}\text { Categorías o tipos } \\
\text { de patrimonio }\end{array}$ & Subcategorías de las manifestaciones & $\begin{array}{l}\text { Descripción de las } \\
\text { manifestaciones }\end{array}$ & $\begin{array}{l}\text { Ubicación y carac- } \\
\text { terísticas }\end{array}$ \\
\hline $\begin{array}{l}\text { Patrimonio } \\
\text { ambiental }\end{array}$ & Áreas de paisaje protegido & & \\
\hline $\begin{array}{l}\text { Patrimonio } \\
\text { arqueológico }\end{array}$ & $\begin{array}{l}\text { Arte rupestre, estructuras líticas, } \\
\text { colecciones arqueológicas }\end{array}$ & & \\
\hline $\begin{array}{l}\text { Patrimonio } \\
\text { arquitectónico }\end{array}$ & $\begin{array}{l}\text { Bienes arquitectónicos de la } \\
\text { modernidad, construcciones }\end{array}$ & & \\
\hline Patrimonio étnico & Etnias urbanas y rurales & & \\
\hline $\begin{array}{l}\text { Patrimonio } \\
\text { demosófico }\end{array}$ & $\begin{array}{c}\text { Mitos y leyendas, gastronomía, } \\
\text { tradiciones, emblemas y cuentos, } \\
\text { festividades, mitos y leyendas, ritos } \\
\text { y costumbres, hábitos }\end{array}$ & & \\
\hline Patrimonio artístico & $\begin{array}{c}\text { Oratoria, saberes, cuentos, música, } \\
\text { danzas, artesanías, murales, } \\
\text { pintura, esculturas }\end{array}$ & & \\
\hline
\end{tabular}

Fuente: Grupo de Investigación Gestión Integral del Territorio - GIT

En este sentido, desde la aproximación teórica, conceptual y metodológica adoptada, el modelo de datos se traduce en una estructura fractal que permite simultáneamente valorar, sintetizar, experimentar, modelar, representar, mapificar, contrastar, retroalimentar y proponer, en diversas escalas de aproximación al territorio, estrategias, programas y proyectos con alto grado de efectividad, no sólo desde la dimensión cultural del desarrollo, sino también desde lo social, ambiental, económico y político.

En el marco de una visión global, la investigación se centra en una localidad de proporciones relativamente pequeñas como es la ciudad de Chinácota en el departamento del Norte 
de Santander y tiende a la recuperación y el fortalecimiento de los valores particulares de la comunidad mediante la espacialización y el manejo adecuado de las manifestaciones del patrimonio tangible e intangible, las cuales serán enfocadas hacia la satisfacción de las necesidades humanas fundamentales, en la medida en que al representar los deseos de los habitantes del lugar y los visitantes, su modo de producción y consumo, permitirán focalizar e incentivar un turismo sostenible $y$, por ende, conllevarán a la reactivación económica y social del municipio (Max Neff, 1986).

El enfoque metodológico corresponde a un enfoque constructivista y ecológico contextual y a sus etapas evolutivas de estructuración del conocimiento, referentes, en primer lugar, a la toma de conciencia respecto de la tendencia global predominante de desarrollo en el territorio. En segundo lugar, a la toma de posicionamiento frente a la tendencia predominante y contratendencias del desarrollo territorial de acuerdo a los intereses de los actores protagónicos del desarrollo desde la oferta y demanda y el reparto equitativo de cargas $y$ beneficios $y$, finalmente, a la negociación de intereses en un nivel posible, pasando de esta manera de un territorio jerarquizado en el ámbito municipal y departamental, a la consolidación de una red policéntrica regional, para llegar de manera paulatina a la conformación una red flexible, polimorfa y multifuncional de relaciones de especialidad y complementariedad entre las ciudades del sistema regional con la capacidad de responder apropiadamente, desde lo local, a las tendencias de desarrollo global.

La descripción de los sucesos y acontecimientos en Chinácota se lleva a cabo al focalizar una muestra representativa de la población y recolectar información de carácter primario y secundario. Luego, mediante dinámicas participativas se analiza la información en una matriz sistémica y se definen las estrategias de transformación de los conflictos, para posteriormente espacializar e interpretar la representación del sentido colectivo que a nivel inconciente articula la ciudad con sus habitantes representado en mapas sociales (cartografía social) y material cartográfico en formatos digitales sistemas de información georreferenciada y geomática.

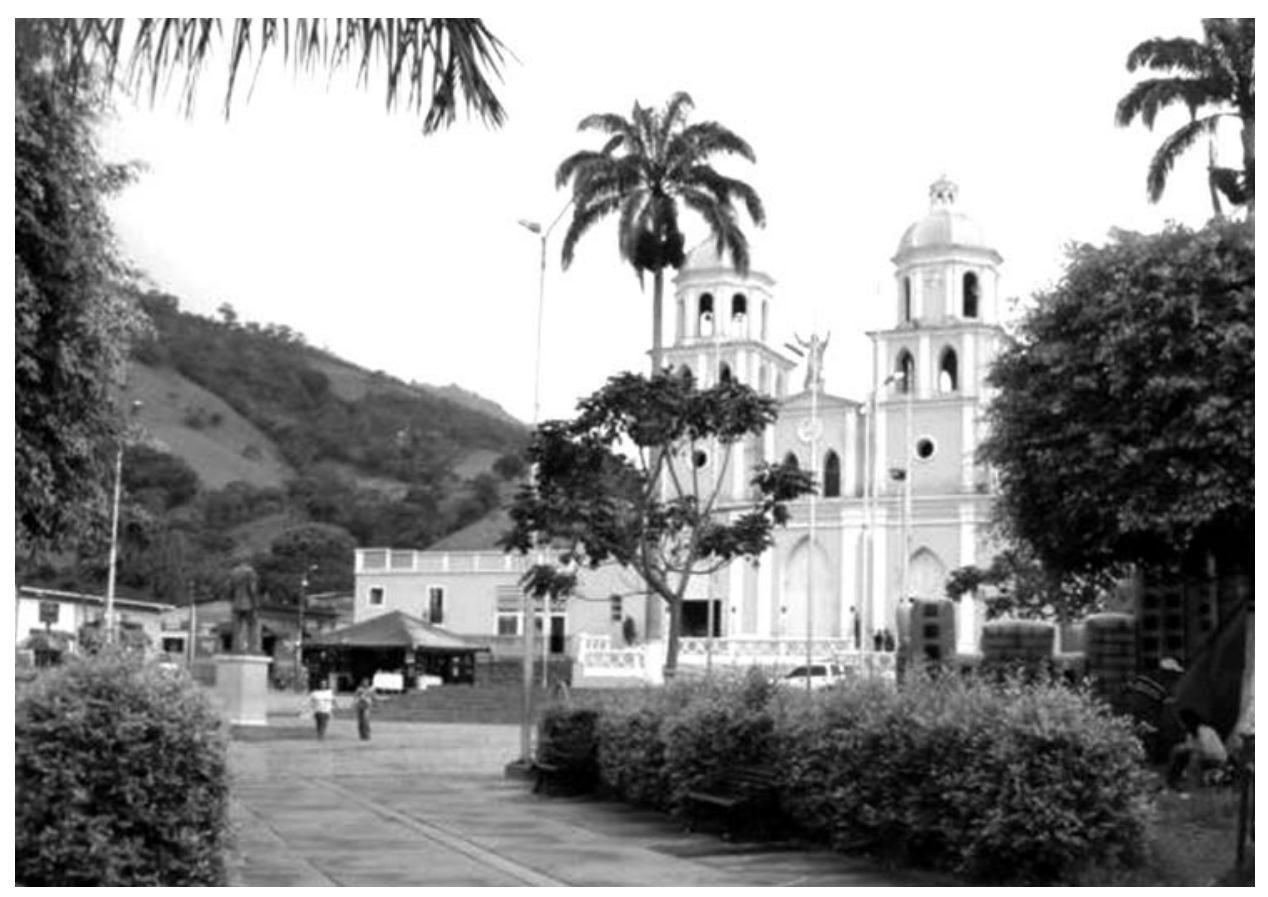

Iglesia Chinácota

Foto: Jemay Mosquera 
De esta manera, se pretende evidenciar que la gestión cultural de los temas del patrimonio tangible e intangible manifiesta múltiples niveles de resolución que requieren un ejercicio de concertación entre agentes sociales protagónicos inmersos en la lógica de relaciones vinculadas con la satisfacción de sus intereses particulares expresados de manera colectiva.

\section{Conclusiones}

El mayor aporte de la propuesta es la apropiación social del conocimiento, la asimilación del tercero incluido y la posibilidad de articular conceptos antagónicos, como lo urbano y lo rural, la ciudad y el campo, lo antrópico y lo natural, lo público y lo privado, entre otros. Lo anterior permite guiar, de manera efectiva, el desarrollo de una localidad o de una región por el poder de la apropiación conciente del territorio a partir de la toma de conciencia del espacio como lugar habitado de manera potencial y emergente por la memoria de propios y extraños y por las manifestaciones reales presentes en el territorio.

El proyecto pretende dotar a la academia y a la comunidad de un modelo de datos que opere dentro de un enfoque sistémico, a partir de unos temas específicos del patrimonio y la cultura local, modelo que se puede replicar tanto en extensividad como en intensividad en cualquier ciudad sin perder el carácter holístico y participativo de la investigación, que posibilite el desarrollo de proyectos que beneficien a la comunidad en todo el espectro de las necesidades humanas fundamentales.

En todo el proceso descriptivo, analítico, interpretativo y propositivo están presentes el diálogo, la recuperación y la recontextualización de saberes, así como la concertación de intereses en pactos colectivos que focalizan los elementos representativos de la realidad local. La sistematización e interpretación de los códigos gráficos y semióticos que expresan la forma y las ideas hacen que, desde el inicio y durante todo el proceso, los resultados de la investigación la retroalimenten y hagan más efectiva.

De esta manera, el mapa cultural desarrollado sobre la base de la planeación participativa permite la creación de sinergias, las cuales una vez desarrolladas favorecerán la redefinición sociocultural de Chinácota hacia un estado más competitivo y le permitirán al municipio insertarse en forma competitiva, equitativa, organizada y sostenida en el desarrollo regional.

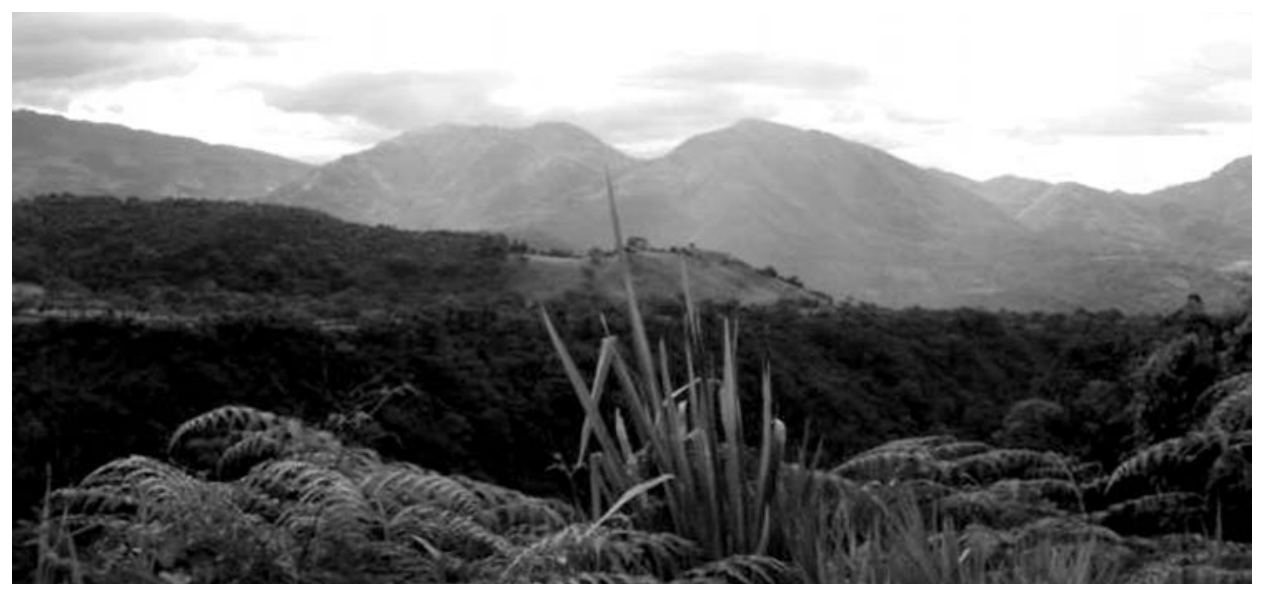

Panorámica Valle del Pamplonita

Foto: Jemay Mosquera 


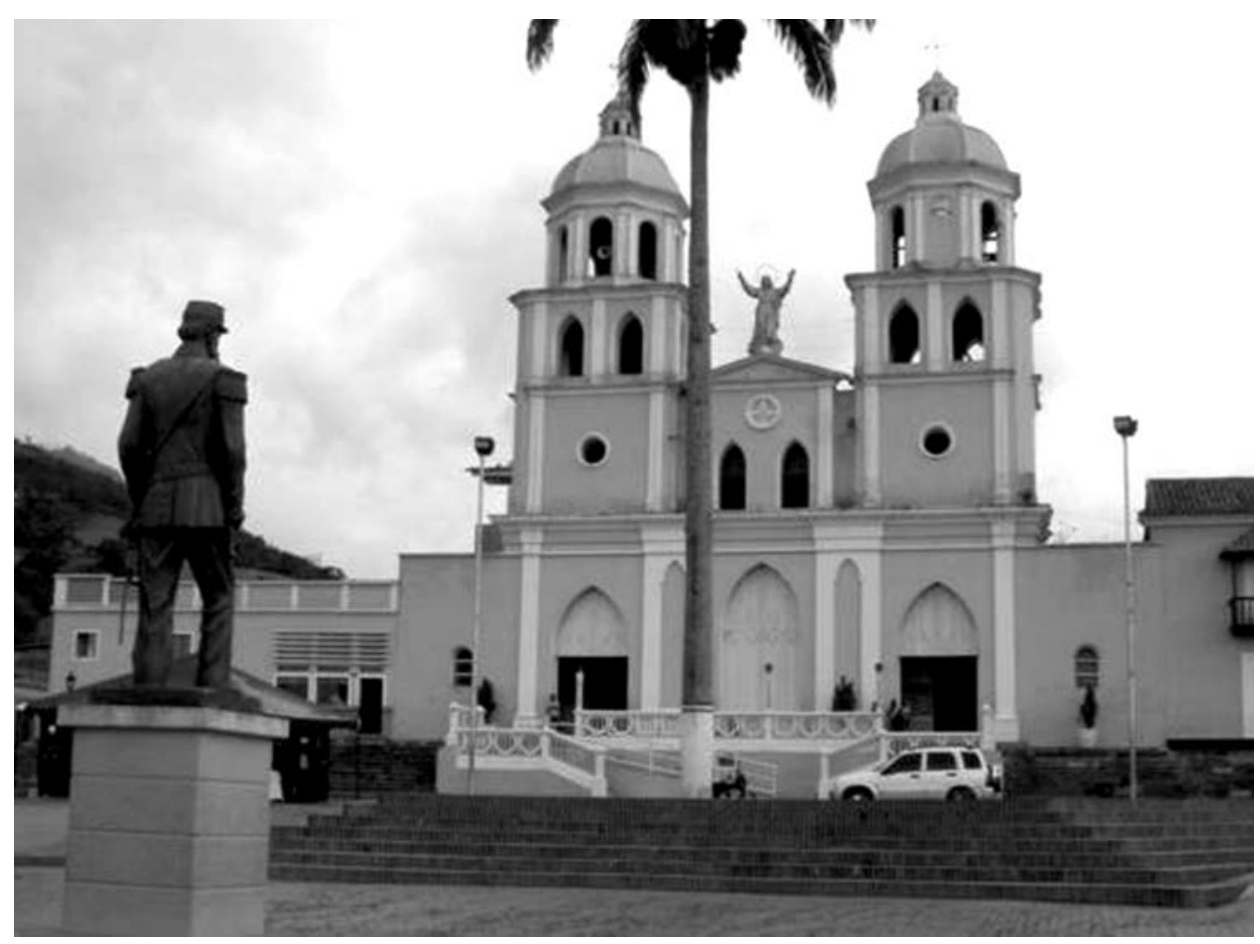

Iglesia Chináota

Foto: Jemay Mosquera

\section{Referencias bibliográficas}

Augé M. Los No Lugares, Espacios del Anonimato. Una antropología de la sobremodernidad, 1993.

Borja M. "La región y la nación en la sociedad global: entre comunidades reales y comunidades imaginadas", en Instituto de Estudios Políticos y Relaciones Internacionales IEPRI. Colombia cambio de siglo. Balances y perspectivas. Bogotá, Planeta. 2000.

Holland, J. Can there be a unified theory of complex adaptive systems? In Morrovitz, H.J. \& Singer, J.L. (Eds), The mind, the brain, and complex adaptive systems. Proceedings Volume XXII, Santa Fe Institute, Studies in the Sciences of Complexity. Reading, MA: Addison-Wesley Publishing Company. 1995.

Lineamientos para el ordenamiento territorial departamental. Ia Ed., Bogotá, Ministerio de Desarrollo Económico. 1997. pp 24-26.

Max Neff M. Desarrollo a Escala Humana - Una Opción para el Futuro -, 1986.

Morín, E. Introducción al pensamiento Complejo. Gedisa. Barcelona, 1997.

Pérgolis J. C. Bogotá Fragmentada: Cultura y Espacio Urbano a fines del Siglo XX, 1998.

Sheldrake R. La presencia del pasado. Resonancia mórfica y hábitos de la naturaleza, Barcelona, Editorial Kairós. 1990. 